\title{
BENEFÍCIOS FISCAIS, PARTILHA DE RECEITAS E A "SÚMULA-FANTASMA" DO STF
}

Coluna publicada em 13.12.2016:<https://www.conjur.com.br/2016-dez-13/ beneficios-fiscais-partilha-receitas-sumula-fantasma-stf $>$

Em 17 de novembro de 2016, o Supremo Tribunal Federal, ao julgar o Recurso Extraordinário 705.423 , tomou uma relevante decisão no âmbito do federalismo fiscal brasileiro, e não pode deixar de ser analisada.

O federalismo fiscal é um dos mais relevantes temas do Direito Financeiro e das finanças públicas em nosso País. Precisa ser mais bem estudado, pois da adequada organização das competências para arrecadar e da partilha de receitas depende o bom funcionamento do Estado brasileiro. Uma difícil equação que precisa ser resolvida para ser capaz de moldar uma estrutura que assegure uma compatibilização entre receitas e despesas, dando a cada um dos entes federados a garantia de suficiência de recursos e independência para obtê-los. ${ }^{1}$

A concentração das preocupações com as questões tributárias faz com que poucos se deem conta de que, na maior parte dos Estados e Municípios, as receitas não vêm da arrecadação de seus próprios tributos, mas sim dos recursos oriundos das receitas partilhadas dos tributos arrecadados por outros entes da federação, principalmente a União.

Para Estados e Municípios, as receitas de tributos partilhados têm uma importância que supera em muito as receitas tributárias próprias, pois dependem dessas transferências intergovernamentais de recursos para compor a maior parcela de seus orçamentos e manter os serviços públicos.

1 Como já mencionei em Transferências voluntárias geram desequilíbrio federativo, nesta edição, p. 19-22. 
Isso não é o ideal para o bom funcionamento do federalismo fiscal, por fazer com que os entes federados subnacionais criem uma dependência de recursos sobre os quais não têm controle, prejudicando severamente sua autonomia financeira, que é um dos pilares nos quais se sustenta nosso federalismo.

Mas é a realidade tal como se apresenta.

E problemas surgem em razão desta distorção.

É o caso, por exemplo, da concessão de benefícios fiscais pelo ente federado com competência para tributar, em impostos cujos recursos são partilhados com outros entes federados.

Ao conceder um benefício fiscal em um tributo que tem suas receitas partilhadas, como ocorre, por exemplo, com a União em relação ao imposto sobre a renda e proventos de qualquer natureza (IR), ou o Imposto sobre Produtos Industrializados (IPI), haverá reflexos em toda a federação, uma vez que as receitas desses impostos são em parte transferidas a todos os demais entes da federação por meio dos Fundos de Participação dos Estados e Distrito Federal (FPE) e dos Municípios (FPM).

Nesse caso, muito provavelmente Estados e Municípios terão redução de suas receitas em face da atitude da União, sobre as quais não têm ingerência e controle, o que poderá gerar consequências graves, uma vez que, em havendo significativa restrição orçamentária, correm o risco de se verem sem os recursos mínimos necessários para cumprirem suas atribuições.

A solução que muitas vezes tem sido prevista é a criação de novas transferências governamentais em razão das perdas decorrentes de renúncias fiscais. Assim, por conta de reduções de receitas originadas das desoneraçôes de impostos partilhados, uma das opções para corrigir desequilíbrios federativos daí decorrentes é a instituição de medidas fiscais compensatórias.

Foi o que ocorreu no caso da exclusão, pela Emenda Constitucional 42/2003, da incidência do ICMS de operações de exportação. Em contrapartida, incluiu-se no Ato das Disposições Constitucionais Transitórias a previsão de que a União entregará aos Estados e ao Distrito Federal, nos termos definidos pela lei complementar, montantes de caráter compensatório às perdas da arrecadação com a exoneração das exportaçōes - montantes que seriam ainda repartidos com os Municípios, como dispõe o artigo 91 do ADCT e seus parágrafos.

O legislador, no entanto, foi até aqui omisso em editar a lei constitucionalmente prevista. Apesar de haver projetos em tramitação e o próprio ADCT adotar regra de transição que prevê a aplicação temporária da Lei Complementar 87/1996 
até a sobrevinda da lei complementar, o caso foi considerado como uma omissão inconstitucional pelo Supremo Tribunal no julgamento ADO $25,{ }^{2}$ em que se estabeleceu o prazo de um ano para suprir a lacuna legislativa. Essa omissão exibe duas importantes facetas do problema: ao mesmo tempo em que, neste caso, o legislador reconheceu o impacto financeiro causado por determinados benefícios fiscais em outros entes da federação, a solução concreta (isto é, a efetiva implantação de mecanismos financeiros compensatórios) não encontrou, ainda, formulação adequada.

Mas não é a única situação em que a disciplina jurídica da renúncia de receitas partilhadas tem levado a muitas outras situações curiosas no âmbito do Direito Financeiro.

Uma delas ocorreu por ocasião da crise econômica de 2008, quando o governo federal brasileiro tomou medidas de renúncias fiscais voltadas a reverter o ciclo descendente da economia que se espalhava por todo o mundo. Houve em razão disto uma severa redução nos repasses aos Municípios, que ficaram em dificuldades financeiras e promoveram movimentos para resolver a questão. A solução encontrada foi uma "ajuda financeira" dada pela União aos Municípios, que se materializou por meio da Medida Provisória 462, de 14 de maio de 2009,3 que "repôs" as perdas com a queda nas receitas decorrentes da diminuição no repasse das transferências do FPM. ${ }^{4}$

Outro fato relevante ocorreu pouco antes, em 18 de junho de 2008, quando o Supremo Tribunal Federal proferiu uma decisão polêmica e interessante no RE 572.762. No caso, o Município de Timbó, no interior de Santa Catarina, se insurgiu contra um benefício fiscal concedido pelo Estado em relação ao ICMS, que, ao postergar o recolhimento do tributo (por meio do Programa de Desenvolvimento da Empresa Catarinense - PRODEC), provocou redução na quota que referido Município recebia a título de participação no ICMS (Constituição, art. 158, IV). Nossa Suprema Corte decidiu que referida parcela "pertence de pleno direito aos Municípios" e que o repasse da referida quota "não pode sujeitar-se à condição

\footnotetext{
2 Ocorrido em 24 de novembro de 2016; veja-se voto do Ministro Gilmar Mendes.

3 Convertida na Lei 12.058 , de 13 de outubro de 2009.

4 MP 462, art. 1 A União prestará apoio financeiro, no exercício de 2009, aos entes federados que recebem o Fundo de Participação dos Municípios - FPM, mediante entrega do valor correspondente à variação nominal negativa entre os valores creditados a título daquele Fundo nos exercícios de 2008 e 2009, antes da incidência de descontos de qualquer natureza, de acordo com os prazos e condições previstos nesta Medida Provisória e limitados à dotação orçamentária específica para essa finalidade.
} 
prevista no programa de benefício fiscal de âmbito estadual", configurando "indevida interferência do Estado no sistema constitucional de repartição de receitas tributárias". Referida parcela integraria "o patrimônio do Município, não podendo o ente maior dela dispor, a seu talante, sob pena de grave ofensa ao pacto federativo". O Min. Ricardo Lewandowski entendeu que tal medida configura verdadeiramente um caso em que "o Estado está fazendo cortesia com o chapéu alheio".

Foi elaborada proposta de Súmula Vinculante, que recebeu o número 30, com a seguinte redação: "É inconstitucional lei estadual que, a título de incentivo fiscal, retém parcela do ICMS pertencente aos municípios”. Controvérsias em relação à redação do texto e alcance do enunciado, que permitiria concluir serem os recursos repassados de titularidade dos entes federados beneficiários, como bem observado por Celso Correia, ${ }^{5}$ levaram à suspensão da publicação da referida súmula. Assim, não obstante já terem sido publicadas as súmulas que se seguiram, esta súmula continua "pendente de publicação" até hoje, tendo se transformado em uma verdadeira "súmula vinculante fantasma". ${ }^{6}$

Mais recentemente, outro caso lança ainda mais dúvidas sobre o futuro da mencionada súmula. No julgamento do RE 705.423, de relatoria do Min. Edson Fachin, citado no início desta coluna, o tema da renúncia de impostos que compõem os fundos de participação volta à tona, em decorrência de ação movida pelo Município sergipano de Itabi, que se insurgiu contra a redução da transferência do Fundo de Participação dos Municípios em razão de benefícios fiscais concedidos pela União. Em sede de repercussão geral, foi aprovada a seguinte tese: "É constitucional a concessão regular de incentivos, benefícios e isenções fiscais relativos ao Imposto de Renda e Imposto sobre Produtos Industrializados por parte da União em relação ao Fundo de Participação de Municípios e respectivas quotas devidas às Municipalidades".

Como bem apontado por Celso Correia e Paula Santos em coluna publicada no ConJur, ${ }^{7}$ a semelhança entre os casos salta à vista, apesar de algumas particularidades. É de todo modo evidente que no RE 572.762 se discutia o repasse de receitas estaduais a Municípios, ao passo que, no RE 705.423, tem-se o caso da

5 CORREIA NETO, Celso de Barros. O avesso do tributo. 2. ed. São Paulo: Almedina, 2016. p. 276.

6 E esperando que não venha a ser conhecida como a súmula "fogosa viúva Porcina", a que "era sem nunca ter sido"...

7 CORREIA NETO, Celso de Barros; SANTOS, Paula Gonçalves Ferreira. Supremo decide quem deve suportar os impactos dos benefícios fiscais federais. Publicada em 24 de novembro de 2016 no ConJur. Disponível em: <http://www.conjur.com.br/2016-nov-24/supremo-decide-quem-suportar-impactos-beneficios-fiscais $>$. 
partilha de receitas federais. Ambos os casos se debruçam, no entanto, sobre questôes jurídicas muito semelhantes, que dizem respeito à possibilidade de redução dos repasses a um ente em razão de renúncias fiscais praticadas por outro.

É muito difícil não reconhecer como contraditórias as decisões. Admitindo-se a tese expressa na Súmula 30 como de aplicação geral, seria inevitável um conflito com a decisão do RE 705.423.

Diante deste cenário, há algumas possibilidades interpretativas quanto às teses defendidas em ambos os recursos. Uma delas, que permitiria alguma forma de conciliação entre ambas as decisões, é a de que o RE 572.762 se referia a uma questão específica, relativa exclusivamente ao tributo catarinense, e que apenas aquele incentivo estadual violaria a autonomia municipal ao diminuir o montante dos recursos partilhados. Mas a hesitação em publicar a Súmula 30 parece diminuir sua força de convencimento perante os tribunais, tanto mais quando se pretende extrapolá-la para outros impostos partilhados, como o IR e o IPI. Até porque, em prevalecendo a tese exposta na "súmula-fantasma", qualquer benefício fiscal envolvendo o IR e o IPI se tornaria pouco viável, uma vez que produz reflexos em todos os Estados e Municípios...

É o caso de perguntar, então, se estaríamos diante de uma revisão da doutrina da "cortesia com chapéu alheio", que parecia estar em vias de formação no espectro da Súmula 30. Em vez disso, teríamos na tese de repercussão geral fixada no RE 705.423 a confirmação de que o poder de tributar tem como contraparte o poder de isentar, e que o ente com tal competência seria dotado em idêntica forma tanto de um como de outro. ${ }^{8}$ E, neste caso, a Súmula 30 seria, de duas, uma: ou uma tese já rapidamente superada em decisões posteriores do próprio Supremo Tribunal Federal, ou uma decisão válida para um caso específico e bem delimitado, não generalizável a outros tantos (o que faria perguntar do porquê, então, da necessidade de se cogitar de uma Súmula Vinculante para tratar da matéria). . De todo modo, parece hoje ainda menos convincente a afirmação que seriam inconstitucionais as

8 Ver ainda Celso CORREIA NETO na coluna publicada em 15 de março de 2015 no ConJur. Disponível em: <http://www.conjur.com.br/2015-mar-14/observatorio-constitucional-supremo-prevalece-controle-formal-beneficios-fiscais >. "É bastante difundida, no pensamento jurídico, a noção de que a cobrança de tributos e a instituição de exoneraçóes são duas faces de uma mesma moeda: o poder de tributar. A competência constitucional que autoriza a imposição de tributos também permite a concessão de benefícios fiscais".

9 Já se discutiu se o RE 572.762-9 constituía um "ponto de inflexão" ou um "ponto fora da curva" na jurisprudência do STF. Ver, a respeito, FREITAS, Leonardo e Silva de Almendra. O passado (RE 572.762/SC) e o futuro (RE 705.423/SE) dos "impostos compartilhados" na jurisprudência do STF: o problema dos incentivos fiscais atuantes antes da arrecadação ("genéricos"). Revista Tributária e de Finanças Públicas, ano 22, vol. 118, set-out. 2014. 
renúncias de receitas com relação a determinados impostos por violarem a autonomia financeira do ente com os quais são partilhados.

Essa é apenas uma das múltiplas dificuldades que integram a difícil construção de um sistema tributário justo e adequado ao nosso Estado federal. Mas que precisa ser superada, pois com mais alguns desses "fantasmas" nosso sistema tributário corre o risco de se transformar em uma "casa mal-assombrada", a assustar diuturnamente os contribuintes e a administração fazendária... 